\title{
Lysogenic Conversion of Staphylococci to Loss of $\beta$-Toxin
}

\author{
By K. C. WINKLER, J. DE WAART AND C. GROOTSEN \\ with the collaboration of \\ B. J. M. ZEGERS, N. F. TELLIER AND C. D. VERTREGT \\ Laboratory of Microbiology, State University, Catharijnesingel 59, \\ Utrecht, Netherlands
}

(Received 2 October 1964)

\begin{abstract}
SUMMARY
Staphylococci may produce $\beta$-toxin and staphylokinase (fibrinolysin). In clinical material there is a preponderance of strains which are $\beta$-toxin negative and kinase positive $\left(\beta^{-} \mathbf{K}^{+}\right)$, but $\beta^{+} \mathbf{K}^{-}, \beta^{-} \mathbf{K}^{-}$and $\beta^{+} \mathbf{K}^{+}$strains also occur. Strains which are $\beta^{+} K^{-}$can be converted by lysogenization with certain phages to loss of $\beta$-toxin and gain of kinase $\left(\beta^{-} \mathbf{K}^{+}\right)$. This is true conversion, since every lysogenized coccus carries the new characters. All the phages which produced this double conversion $\left(\beta^{-} \mathrm{K}^{+}\right.$phages $)$belong to the serological group F. The conversion is due to two separate loci on the phage which are active in the prophage state. These loci have not been found in phages of other serological groups ( $\beta^{0} \mathrm{~K}^{0}$ phages). The $\beta$-toxic and fibrinolytic properties of staphylococci are not always phage-dependent; strains which do not carry detectable phages or carry only $\beta^{0} \mathrm{~K}^{0}$ phages can be either $\beta^{+} \mathbf{K}^{-}, \beta^{-} \mathbf{K}^{+}, \beta^{+} \mathbf{K}^{+}$or $\beta^{-} \mathbf{K}^{-}$, implying the occurrence of structural loci on the bacterial genome. Several strains with the phage-typing pattern $80 / 81$ or a related pattern, which are $\beta^{-} \mathbf{K}^{+}$, were found to carry converting phages. On loss of these phages the strains became $\beta^{+} \mathbf{K}^{-}$and showed a change of typing-pattern, gaining sensitivity for phages of group III.
\end{abstract}

\section{INTRODUCTION}

Lysogenization of certain strains of Staphylococcus aureus which produced $\beta$ haemolysin with phages belonging to the serological group $F$ resulted in the loss of the ability to form $\beta$-toxin (De Waart, Winkler \& Grootsen, 1962; De Waart, 1964). This proved to be a true lysogenic conversion (phage conversion) since each lysogenized coccus lost the character and each colony which did not produce $\beta$-toxin proved to be lysogenic. More recently a large number of parent strains and lysogenized strains were tested for the production of staphylokinase (fibrinolysin). Conversion to loss of $\beta$-toxin was always associated with the gain of staphylokinase. Strains which produced $\beta$-toxin but no kinase $\left(\beta^{+} \mathbf{K}^{-}\right)$were thus simultaneously converted with regard to two properties into staphylococci of the phenotype $\beta-K^{+}$. The mechanism of this conversion was studied.

\section{METHODS}

Organisms used. All strains of staphylococcus were coagulase positive and typable with the basic set of typing-phages (Blair \& Williams, 1961). Apart from the propagating strains of the standard phage-typing set, strain Wood 46 and one 
strain isolated from a chicken, all other strains had been isolated from human clinical material in various hospitals.

The strains in phage-group II were described by Winkler \& Grootsen (1961). Strain 879 with phage pattern $3 \mathrm{~B} / 3 \mathrm{C} / 55 / 71$ was $\beta^{+} \mathrm{K}^{-}$on isolation and could not be shown to be lysogenic in tests with several hundred staphylococcal strains. Strains 756 and 269 with the same phage pattern, and strains 184 and 84 with phage pattern 3A/3B/3C/55/71, had the same properties but were obtained from lysogenic $\beta-K^{+}$strains which had lost phage spontaneously.

Strain $\mathbf{5 7}$ was sensitive to all phages in groups I and III, and was also $\beta^{+} \mathbf{K}^{-}$and not demonstrably lysogenic in hundreds of tests. Two variants of strain 57 were used; $57(\alpha+\beta)$ produced $\alpha$ - and $\beta$-toxin, $57 \beta$ produced mainly $\beta$-toxin; many of the experiments were done with the non-lysogenic strains 879, 269 and 57. Some additional strains will be described in the text.

Lysogenic strains will be indicated by the number of the parent strain followed by the number of the phage in parenthesis.

Strains kept well in stab cultures in meat-broth agar at room temperature. Each experiment was started from a single colony on a sheep-blood agar plate derived from the stock culture. Difco nutrient broth and Difco nutrient agar with added $\mathrm{CaCl}_{2}$ (87.6 mg./100 ml.) were used in all experiments.

Phages. Most phages were derived from wild-type strains by induction with ultraviolet (u.v.) radiation (Morse, 1962). The phages in lytic group II described by Winkler \& Grootsen (1961) were arranged in three groups, $\gamma, \delta$ and $\epsilon$ according to their lytic spectra on fifty strains. The phages within each group are probably coimmune. Group $\gamma$ and $\delta$ are more closely related than $\gamma$ and $\epsilon$ or $\delta$ and $\epsilon$. Of the $\gamma$ phages, 756 and 184 lysed propagating strains (PS) 3в, 3c, 55 and 71, and 780, 84, 246 and 285 lysed PS 3B, 3c and 55. The $\delta$ phages $(269,764,334,681$ and 763) lysed PS3C and 55, and PS3A weakly. The $\epsilon$ phages (491, 273 and 509) lysed PS3B and 71.

The phages $3 \mathrm{C}, 71,77$ and $42 \mathrm{D}$ from the basic set were also used. Some phages were isolated from propagating strains of the basic set, e.g. phage L80 from strain PS 80, phage L55 from strain PS 55, phage L6 from strain PS6, phage L 7 from strain Ps7. Phage W 46 was isolated from strain Wood 46, the well-known $\alpha$-toxin producing strain.

Phage-typing was done by standard techniques (Blair \& Williams, 1961). Phage methods were as described by Adams (1959). Staphylococcal strains were lysogenized by spotting the phages on flooded plates. The secondary growth was suspended in broth and spread on sheep-blood agar plates; $\beta^{+}$and $\beta^{-}$colonies were easily distinguishable on these plates. Many colonies (from ten to several hundreds depending on the case) were tested for lysogenicity and immunity by cross-streaking with the phage and the indicator strains. In more quantitative experiments about $10^{8}$ phage particles and $10^{8}$ cocci were mixed, incubated for $5 \mathrm{~min}$. and centrifuged. The numbers of surviving cocci and of plaque-forming units were determined in the supernatant fluid and in the sediment. Several hundreds of survivor colonies were scored for $\beta$-toxin on sheep-blood agar plates, and for lysogenicity by replicating on indicator plates or by cross-streaking (de Waart et al. 1962, table 1).

Toxin production. Toxic filtrates were produced by inoculating $1 \mathrm{ml}$. of an $8 \mathrm{hr}$ culture into $100 \mathrm{ml}$. Todd-Hewitt broth in screw-capped bottles of 1 l. capacity 
The bottles were then gassed with air $+10 \%(\mathrm{v} / \mathrm{v}) \mathrm{CO}_{2}$, closed and shaken at $37^{\circ}$. $\beta$-Toxin began to appear at $6 \mathrm{hr}, \alpha$-toxin several hours later. At $8 \mathrm{hr}$ the culture fluid contained $\beta$-toxin without $\alpha$-toxin; at $16 \mathrm{hr}$ the amount of both toxins was maximal. For routine use, culture fluids were harvested at $16 \mathrm{hr}$.

Crude culture filtrates and more purified preparations precipitated with $60 \%$ saturated $\left(\mathrm{NH}_{4}\right)_{2} \mathrm{SO}_{4}$ were titrated for $\beta$-toxin and $\alpha$-toxin by incubation of serial dilutions with a $2 \%(\mathrm{v} / \mathrm{v})$ suspension of washed red cells from sheep or rabbit in veronal buffer for $1 \mathrm{hr}$ at $37^{\circ}$ and $4 \mathrm{hr}$ at $4^{\circ}$. Haemolysis (100\%) was read visually or $50 \%$ haemolysis was determined with an EEL colorimeter. Antitoxins were prepared by injecting rabbits with formalinized $\alpha$-toxin and $\beta$-toxin adsorbed on $\mathrm{AlPO}_{4}$.

Production of anti- $\beta$-toxin. Since antisera containing anti- $\beta$-toxin but no anti- $\alpha$ toxin seem difficult to obtain, the production of anti- $\beta$-toxin may be described) Staphylococcus strain 269 was cultured in Todd-Hewitt broth under $10 \%(\mathrm{v} / \mathrm{v})$ $\mathrm{CO}_{2}$ as described. The fluid was harvested after $7 \mathrm{hr}$ and centrifuged. (Since it is now known that strain 269 does not produce $\alpha$-toxin $16 \mathrm{hr}$ cultures may also be used.) The combined supernatant fluids from 10 bottles had a titre of 50 for sheep red cells, whereas the titre for rabbit cells was negligible $(<1)$. $1350 \mathrm{ml}$. of a saturated solution of ammonium sulphate (Merck p.a.) were added to each litre of supernatant fluid and the mixture kept at $4^{\circ}$ for $16 \mathrm{hr}$. After centrifugation the sediment was dissolved in $0 \cdot 15 \mathrm{M}$-phosphate buffer ( $\mathrm{pH} 6 \cdot 8$ ) and dialysed in a cellophan (Nojax) bag against $300 \mathrm{ml}$. buffer for $3 \mathrm{hr}$ on a magnetic stirrer, the buffer being replaced each hour. The resulting brown fluid had a titre for sheep red cells of 1000. The titre for rabbit cells was $<1$.

Toxoid was prepared by adding $1 \mathrm{ml}$. of a $10 \%(\mathrm{w} / \mathrm{v})$ solution of formaldehyde to $10 \mathrm{ml}$. of toxin solution and incubating for 3-4 days at $37^{\circ}$. The titre for sheep red cells was decreased to below 1. Excess of formaldehyde was eliminated by dialysis against buffer. The toxoid was brought to $\mathrm{pH} 5 \cdot 4$ with $5 \%(\mathrm{w} / \mathrm{v}) \mathrm{HCl}$ and one volume of a suspension of $25 \mathrm{mg}$. $\mathrm{AlPO}_{4} / \mathrm{ml}$. was added. The mixture was incubated overnight at $37^{\circ}$ and kept at $4^{\circ}$. Rabbits were injected subcutaneously in the abdominal wall on days $1,3,5$ and 7 with respectively $1,3,5$ and $7 \mathrm{ml}$. of this toxoid. Ten days later serum was obtained and tested for antitoxin. The amount of serum that neutralized $10050 \%$ haemolytic doses (HD 50) was taken as a unit of antitoxin (AU). Sera of about $50 \mathrm{AU} / \mathrm{ml}$. were obtained.

Staphylokinase. Kinase was demonstrated by the production of a clear zone on nutrient agar plates containing heated $\left(20 \mathrm{~min} ., 56^{\circ}\right.$ ) rabbit plasma (Lack \& Wailling 1954). Soya bean trypsin inhibitor did not decrease the zone. No zones were produced on fibrinogen without plasminogen. Culture filtrates containing kinase were produced by shaking cultures of $50 \mathrm{ml}$. Todd-Hewitt broth in screw-capped bottles at $30^{\circ}$, with air as gas phase. Precipitation with 4 vol. of ethanol (Gerheim, Ferguson \& Travis, 1947, 1948; Gerheim, 1948; Gerheim, Ferguson, Travis, Johnston \& Boyles, 1948) produced an appreciable concentration without loss of activity. A purification by the method of Glanville (1963) was confirmed but was not used for the work reported in this paper. A rough assay by a cup-plate method on agar plates with heated rabbit plasma in Michaelis buffer $(\mathrm{pH} 7$ ) was used for testing. The amounts of kinase were expressed in $\mu \mathrm{g}$. of a crude (standard) preparation. 


\section{RESULTS}

Simultaneous conversion to loss of $\beta$-toxin and to kinase production

Staphylococcus strain 879 produces $\alpha$-toxin and $\beta$-toxin but no kinase. After lysogenization with some of the $\gamma, \delta$ and $\epsilon$ phages described under Methods, the lysogenized strains had lost the $\beta$-haemolytic character as tested on sheep blood agar and produced kinase as tested on heated rabbit-plasma agar. The haemolytic activity of culture filtrates of the lysogenized strains on sheep red cells decreased by a factor 10 or more. A selection of results is presented in Table 1 . The conversion of strain 879 from $\beta^{+} \mathbf{K}^{-}$to $\beta^{-} \mathbf{K}^{+}$was produced by the first seven phages shown. It was also produced by phages $184,780,764,334,681$ and 763 which have been omitted from the table. The conversion was not produced by the three phages of serological groups $\mathbf{A}$ and $\mathbf{B}$ or by phage 509 which also belongs to group $\mathbf{F}$.

\section{Table 1. Influence of lysogenization on the production of $\beta$-toxin and} staphylokinase by Staphylococcus strains

$\mathbf{R}$ and $\mathbf{S}=$ reciprocal of dilution of standard culture filtrate giving $\mathbf{5 0} \%$ haemolysis with rabbits cells and sheep cells, respectively. $r=$ ratio of $S$ of parental and lysogenized strain. $\mathbf{K}=$ kinase test on heated rabbit plasma.

Strain no.

$\begin{array}{cc}\text { Origin of } & \begin{array}{c}\text { Serological } \\ \text { group of } \\ \text { phage* }\end{array}\end{array}$

Strains in phage group II

879
$879(756)$
$879(84)$
$879(246)$
$879(285)$
$879(269)$
$879(273)$
$879(491)$
$879(509)$
$879(\mathbf{L} 55)$
$879(71)$
$879(3 \mathrm{c})$
269
$269(269)$

$\gamma$
$\gamma$
$\gamma$
$\gamma$
$\gamma$
$\delta$
$\epsilon$
$\epsilon$
$\epsilon$
Ps55
St
St

$\delta$

Strains in phage groups

I and III

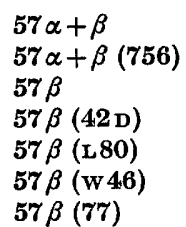

\begin{tabular}{|c|c|c|c|c|}
\hline . & & 575 & 2030 & \\
\hline$\gamma$ & $\mathbf{F}$ & 511 & 59 & $\mathbf{3 4}$ \\
\hline & & 34 & 304 & . \\
\hline St & $\mathrm{F}$ & 81 & 6 & 50 \\
\hline PS 80 & $\mathbf{F}$ & 51 & $\mathbf{3}$ & 101 \\
\hline Wood 46 & $\mathbf{F}$ & 30 & $\mathbf{3}$ & 101 \\
\hline St & $\mathbf{F}$ & . & 200 & . \\
\hline
\end{tabular}

* $\gamma, \delta, \epsilon=$ phages described by Winkler \& Grootsen; $\mathrm{St}=$ phages from standard phage-typing set; PS 55, PS 80 , Wood 46 indicate that the phages were isolated from these strains.

The experiment was repeated with Staphylococcus strain 184 which was again converted by the $\mathbf{F}$ phages 184, 756, 285 and 269, but not by the A phage L55 or the $B$ phage 71 (not in Table 1). With strain 269 analogous results were obtained. 
Consequently 13 out of 14 of the group F phages of lytic group II gave the conversion of both characters. Since the phages within each of the $\gamma, \delta$ and $\epsilon$ groups are co-immune, these 13 phages probably represent only three unrelated instances of the phenomenon. It was shown earlier that the change of properties was due to true conversion. It should perhaps be added that occasional $\beta$-haemolytic colonies which were non-lysogenic could be isolated from the lysogenized strains, showing that the conversion was reversible.

In the hope of extending the material outside Staphylococcus strains of group II, strain 57, which is $\beta^{+} \mathrm{K}^{-}$and sensitive to all phages of lytic groups I and III, was used to test the basic set of phages and over 50 phages from natural strains. Only three further instances of double conversion were found as shown in the second part of Table 1 . The three converting phages proved to belong to the serological group $\mathbf{F}$. However, the $\mathrm{F}$ phage 77 did not convert. The serological type of all the nonconverting phages was not studied, but strain 57 was not converted by phages 6,7 and $\mathbf{8 1}$ from the basic set which belong to serological group $\mathbf{A}$. These results show that some phages are able to convert $\beta^{+} \mathbf{K}^{-}$strains to $\beta^{-} \mathbf{K}^{+}$. They seem to occur only in serological group F, though not all group $\mathbf{F}$ phages carry this property.

By neutralization experiments with anti- $\alpha$ and anti- $\beta$-toxin (Table 2 ) it was shown that $\beta$-toxin production was absent from the converted strains and that the residual haemolysis of sheep red cells was due to other toxins ( $\alpha$-toxin, $\delta$-toxin).

Table 2. Neutralization of haemolysins of a parental and a lysogenized strain of Staphylococcus by pure anti- $\alpha$-toxin and anti- $\beta$-toxin

$\mathbf{R}$ and $\mathbf{S}$ are reciprocals of $\mathbf{5 0} \%$ haemolysis titre against rabbit and sheep red cells, respectively.

\begin{tabular}{|c|c|c|}
\hline & $\mathbf{R}$ & $\mathbf{S}$ \\
\hline \multicolumn{3}{|l|}{ Strain 879} \\
\hline Culture filtrate & 70 & 937 \\
\hline + normal serum & 63 & 660 \\
\hline+1.8 units anti- $\alpha$-serum & 1 & 731 \\
\hline+2 units anti- $\beta$-serum & 79 & 2 \\
\hline \multicolumn{3}{|l|}{ Strain 879 (756) } \\
\hline Culture filtrate & 296 & 53 \\
\hline + normal serum & 276 & 22 \\
\hline+1 unit anti- $\alpha$-serum & 2 & $\mathbf{0}$ \\
\hline+2 units anti- $\beta$-serum & 610 & 15 \\
\hline \multicolumn{3}{|l|}{ Strain $57 \alpha+\beta$} \\
\hline Culture filtrate & 624 & 1500 \\
\hline$+1 \cdot 8$ units anti- $\alpha$-serum & 2 & 1380 \\
\hline+2 units anti- $\beta$-serum & 650 & 69 \\
\hline \multicolumn{3}{|l|}{ Strain $57 \alpha+\beta(756)$} \\
\hline Culture filtrate & 648 & 82 \\
\hline+1.8 units anti- $\alpha$-serum & 2 & 15 \\
\hline+2 units anti- $\beta$-serum & 661 & $\mathbf{5 1}$ \\
\hline
\end{tabular}

\section{Independent character of $\beta$-toxin and staphylokinase}

Christie \& Wilson (1941) and Rountree (1947) noticed that $\beta$-toxin and kinase were not often produced by the same Staphylococcus strain or, in other words, that $\beta^{+} \mathbf{K}^{-}$strains and $\beta^{-} \mathbf{K}^{+}$strains were frequent and $\beta^{-} \mathbf{K}^{-}$or $\beta^{+} \mathbf{K}^{+}$strains rare. Analogous observations were made by Willis, Jacobs \& Goodburn (1963). The 
possibility that kinase broke down the $\beta$-toxin or interfered with its action, or that $\beta$-toxin broke down or interfered with kinase, was excluded by incubating preparations of both enzymes together and subsequently measuring their activity (Table 3 ). Since the activity of both enzymes was found to be unimpaired, inactivation or interference was not the cause of the observed correlation. Since purified kinase is not haemolytic (Glanville, 1963) and kinase preparations are not neutralized by anti- $\beta$-toxin (Table 3 ), kinase and $\beta$-toxin can be considered as separate proteins.

Table 3. Absence of interaction between kinase and $\beta$-toxin

\begin{tabular}{|c|c|c|c|c|c|}
\hline $\begin{array}{l}\text { Staphylo- } \\
\text { kinase } \\
\text { (ml.) }\end{array}$ & $\begin{array}{l}\text { Staphylo- } \\
\text { coccus } \\
\beta \text {-toxin } \\
\text { (ml.) }\end{array}$ & $\begin{array}{c}\text { Broth } \\
\text { (ml.) }\end{array}$ & $\begin{array}{l}\text { Anti- } \beta \\
\text { toxin } \\
\text { (ml.) }\end{array}$ & $\begin{array}{l}\text { Staphylo- } \\
\text { kinase } \\
\text { (mg.) }\end{array}$ & $\begin{array}{c}\text { Staphylococcus } \\
\beta \text {-toxin } \\
\text { HD50 doses }\end{array}$ \\
\hline 1 & . & 1 & . & 20 & . \\
\hline 1 & 1 & . & . & 30 & 2000 \\
\hline . & $\mathbf{I}$ & 1 & . & . & 2000 \\
\hline 1 & . & . & 1 & 25 & . \\
\hline
\end{tabular}

\section{Strains with various combinations of $\beta$-toxin and kinase}

Lysogenic conversion of staphylococcal strains from $\beta^{+} \mathbf{K}^{-}$to $\beta^{-} \mathbf{K}^{+}$and the reversal by loss of phage can be interpreted by considering the lysogenized strains as partial diploids with $\beta^{+}$and $\mathrm{K}^{-}$genes on the bacterial genome and dominant $\beta^{-}$and $\mathrm{K}^{+}$genes on the prophage. The various combinations of properties in staphylococcal strains might then be caused by variation in the bacterial genome, as well as in the phage genome. It seemed of interest to examine the frequency of phage involvement and of the distribution of types. That many naturally occurring $\beta-\mathbf{K}^{+}$ Staphylococcus strains do not easily yield a converting phage had already become apparent in the lysogenization experiments with strain 57.

Strains with unusual combinations such as $\beta^{-} \mathbf{K}^{-}$and $\beta^{+} \mathbf{K}^{+}$were sought. Among the propagating strains of the standard set PS 6, PS 7 and PS 73 proved to be $\beta-K^{-}$. Among 40 naturally occurring strains, selected at random from a collection of $\mathbf{3 0 0 0}$ strains, two $\beta-K^{-}$strains were found, i.e. strain 1835 (isolated 25. iv. 1961 from a nasal swab) with phage pattern $47 / 70 / 73 / 42 \mathrm{E}$ and strain 8289 (isolated 15. i. 1962 from a chicken) with pattern $52 \mathrm{~A} / \mathbf{7 9} / 80$. No true $\beta^{+} \mathbf{K}^{+}$strain was found in this series. Later strain 891 , with phage-pattern $44 / 70(29 / 44 \mathrm{~B} / 52 / 52 \mathrm{~A} / 6 / 7 / 53 / 83 \mathrm{~A}$ weak) was found to be truly $\beta^{+} \mathbf{K}^{+}$. These six strains were tested for lysogenicity against all propagating strains and against strains 879 and 57 . Where phages were present, the filtered lysates obtained by induction and purified phages propagated on suitable strains were tested for converting properties. No converting phages were found, though some strains carried non-converting $\left(\beta^{0} \mathrm{~K}^{0}\right)$ phages. This enabled us to classify the six new strains together with the strains in Table 1 in groups according to the $\beta$ and $\mathbf{K}$ character of the bacterial genome, and according to the presence (as far as detected) of converting and non-converting phages. The results are shown in Table 4. 
The strains discussed in Table 1 are listed in Table 4 (by a few representatives only) in column $\mathrm{C}\left(\beta^{+} \mathbf{K}^{-}\right)$. The first row contains those that were not demonstrably lysogenic, the second row the strains carrying non-converting $\left(\beta^{0} \mathrm{~K}^{0}\right)$ phages, and the third row the strains containing converting phages.

The five new $\beta^{-} \mathbf{K}^{-}$strains are in column B. Staphylococcus strains PS73 and 1835 are in the first row as they proved to be not demonstrably lysogenic. Staphylococcus strains PS6, PS7 and 8289 are in the second row as they carried non-converting phages. The crude induced phages from strains PS 6 and $\mathrm{PS} 7$, as well as purified propagated phages from these strains, were used to lysogenize strain $891\left(\beta^{+} K^{+}\right)$.

\section{Table 4. Various combinations of the characters $\beta$ ( $\beta$-toxin) and $\boldsymbol{K}$ (kinase) in Staphylococcus}

Columns A, B, C and D refer to strains which carry the combination $\beta^{+} \mathbf{K}^{+}, \beta^{-} \mathbf{K}^{-}$, $\beta^{+} \mathbf{K}^{-}$and $\beta^{-} \mathbf{K}^{+}$when not converted (bacterial genotype). The strains in row 1 are nonlysogenic. Those in row 2 carry a non-converting phage $\left(\beta^{0} \mathrm{~K}^{0}\right)$. In these cases the phenotype is identical with the genotype of the staphylococcus. Row 3 contains the strains carrying converting phages $\left(\beta^{-} \mathbf{K}^{+}\right)$. The strains show the $\beta$ and $\mathbf{K}$ character of the converting phage. The Roman numbers indicate the phage group (Williams $\&$ Rippon, 1952) to which the strain belongs.

\begin{tabular}{|c|c|c|c|c|}
\hline & $\mathbf{A}$ & B & C & $\mathbf{D}$ \\
\hline $\begin{array}{l}\text { Row } 1 . \\
\text { Non-lysogenic }\end{array}$ & $\begin{array}{l}\beta+K^{+}(-) \\
891(\text { III })\end{array}$ & $\begin{array}{l}\beta^{-} \mathbf{K}^{-}(-) \\
\text {Ps 73 (III) } \\
1835 \text { (I) }\end{array}$ & $\begin{array}{l}\beta^{+} K^{-}(-) \\
879 \text { (II) } \\
184 \text { (II) } \\
269 \text { (II), etc. } \\
\quad 57 \text { (I-III) }\end{array}$ & $\begin{array}{l}\beta^{-\mathbf{K}^{+}}(-) \\
\mathbf{3 A}_{\mathbf{A}}(\mathrm{II})\end{array}$ \\
\hline $\begin{array}{l}\text { Row 2. Carrying } \\
\text { non-converting } \\
\text { phages }\end{array}$ & $\begin{array}{l}\beta^{+} \mathbf{K}^{+}\left(\phi \beta^{0} \mathbf{K}^{0}\right) \\
891(\mathbf{L} 6) \text { III } \\
891(\mathbf{L} 7) \text { III }\end{array}$ & $\begin{array}{l}\beta-\mathbf{K}-\left(\phi \beta^{0} \mathbf{K}^{0}\right) \\
\text { PS } 6 \text { (III) } \\
\text { Ps 7 (III) } \\
8289\end{array}$ & $\begin{array}{l}\beta^{+} \mathrm{K}^{-}\left(\phi \beta^{0} \mathrm{~K}^{0}\right) \\
879(509) \text { II } \\
879(\mathbf{L} 5) \text { II } \\
879(71) \text { II } \\
57(77) \text { I-III } \\
57(8289) \text { I-III }\end{array}$ & $\begin{array}{l}\beta^{-} \mathbf{K}^{+}\left(\phi \beta^{0} \mathbf{K}^{0}\right) \\
\text { many wild-type } \\
\text { staphylococci }\end{array}$ \\
\hline $\begin{array}{l}\text { Row 3. All } \\
\text { strains converted } \\
\text { to } \beta^{-} K^{+}\end{array}$ & & $\begin{array}{l}\beta-K^{-}\left(\phi \beta-K^{+}\right) \\
\text {PS6 (w } 46) \text { III } \\
\text { PS 7 (w 46) III } \\
\text { PS'73 (w 46) III }\end{array}$ & $\begin{array}{l}\beta^{+} \mathrm{K}^{-}\left(\phi \beta-\mathrm{K}^{+}\right) \\
879(756) \mathrm{II} \\
184(184) \mathrm{II} \\
57(\mathrm{~L} 80) \mathrm{I} \\
57(\mathrm{w} 46) \mathrm{I}-\mathrm{III}\end{array}$ & \\
\hline
\end{tabular}

No $\beta^{-}$colonies were detected among several hundred colonies of the secondary growth, i.e. no conversion was observed. The phage from strain $\mathbf{8 2 8 9}$ was used in the same way to lysogenize, strain 57; no conversion was observed. (The lysogenized strain 57 (8289) is added in column $\mathrm{C}$, row 2.) These results seem to indicate that strains PS 6, PS 7 and 8289 did not carry converting phages. That PS6, PS 7 and also Ps 73 did indeed not carry converting phages was proved beyond doubt by lysogenizing them with the converting phage $W 46$ : the resulting strains were converted to $\beta^{-} \mathbf{K}^{+}$. Obviously the converting $\left(\beta^{-} \mathbf{K}^{+}\right)$phage $\mathbf{W} 46$ cannot suppress $\beta$-toxin production in a strain which does not produce any. These converted strains are consequently placed in column $\mathrm{B}$, row 3 . The $\beta^{+} \mathrm{K}^{+}$strain 891 was not demonstrably lysogenic and is put in column $A$, row 1 ; by lysogenization with the phages $\mathrm{L} 6$ and $\mathrm{L} 7$ the strain was not converted. These lysogenized strains are put in column A, row 2. In column D only Staphylococcus strain Ps $3 \mathbf{A}$ is cited as an instance of a strain with characters $\beta^{-} \mathbf{K}^{+}$which was not demonstrably lysogenic. 
Many naturally occurring strains which carry $\beta^{0} \mathrm{~K}^{0}$ phages would belong in column $D$, row 2. It has already been mentioned that only a few of them yield converting phages. Whether the $\beta-K^{+}$character might be due to a defective converting phage is of course difficult to decide.

Considering these data it is obvious that staphylococcal strains with the characters $\beta^{+} \mathbf{K}^{-}$and $\beta^{-} \mathbf{K}^{-}$and not carrying a converting phage occur in nature. This is probably also true of the characters $\beta-\mathbf{K}^{+}$and $\beta^{+} \mathbf{K}^{+}$, though defective phages of the type $\beta^{-} \mathbf{K}^{+}$and $\beta^{0} \mathbf{K}^{+}$cannot be excluded. In any case, it can be concluded that $\beta$-toxin and kinase production are separate properties of staphylococci which can be independent of prophage. Furthermore, it is clear from row 3 that until now only converting phages of the type $\beta-\mathrm{K}^{+}$have been found, and conversion of $\beta-\mathrm{K}^{-}$ strains (column B) and $\beta^{+} \mathbf{K}^{-}$strains (column $\mathrm{C}$ ) always results in $\beta^{-} \mathbf{K}^{+}$strains. This does not preclude the occurrence of converting phages of the types $\beta^{0} \mathrm{~K}^{+}$, $\beta^{-} \mathbf{K}^{0}$ or even $\beta^{+} \mathbf{K}^{+}$and $\beta^{-} \mathbf{K}^{-}$.

\section{Converting phages in Staphylococcus strains with phage pattern 80/81}

In the hope of finding converting phages of these other types, 40 strains of Staphylococcus from our collection and some propagating strains were screened for the $\beta^{+} \mathbf{K}^{+}$and $\beta^{-} \mathbf{K}^{-}$phenotype. The $\beta^{-} \mathbf{K}^{-}$strains have already been discussed. The strains were taken straight from old stock cultures and spotted on sheep-blood agar and heated-plasma agar. Three strains were presumably $\beta^{+} \mathbf{K}^{+}$, but on plating out they proved to be mixtures of stable variants (called $\mathbf{A}$ and $\mathbf{B}$ ) which were respectively $\beta^{-} \mathbf{K}^{+}$and $\beta^{+} \mathbf{K}^{-}$, and also differed in phage-typing pattern (Table 5; strains no. 1330, 1451, Ps 81). Analysis of these strains showed that the $\beta^{-} \mathrm{K}^{+}$ strains carried a converting phage which was absent from the $\beta^{+} \mathbf{K}^{-}$variant. Both variants also carried a $\beta^{0} \mathrm{~K}^{0}$ phage which complicated the demonstration of the converting phages. The phages from strains $1330 \mathrm{~A}$ and $1451 \mathrm{~A}$ produced small plaques on strains 1330B and on PS 80 . The phage from strain Ps $81 \mathrm{~A}$ was different and produced small plaques on strains $1330_{\mathrm{B}}$ and 57 . The phages from the $\mathrm{B}$ strains (carrying the $\beta^{0} \mathbf{K}^{0}$ phages) did not react with these indicator strains. The $\mathbf{B}$ variants should consequently be placed in column $\mathrm{C}$ of row 2 in Table 4 and the A variants in row 3.

When it was realized that the three $\mathbf{A}$ strains all had the phage-typing pattern $80 / 81,10$ other strains which had shown this and related patterns on isolation were taken from our collection, more or less at random. Though some strains were from the same hospital they had been isolated several months apart and can be considered as independent isolations. The strains were taken from old stock cultures as before. In four cases mixtures of A and B variants were found, suggesting that this variation is not rare in old stock cultures. The four strains were nos. 920, 957, 1550, 1629 in Table 5. By chance the same variation was observed in strain Ps 80. The variant from strain PS 80 yielded a phage which could be propagated on strains Ps $80 \mathrm{~B}$ or 57. Phage L 80 proved to belong to the serological group F in conformity with the results of Rountree (1959).

Several of the B strains from Table 5 could be lysogenized by phage L80 and converted to strains with the properties of A strains. The phages from the A variants thus seem to have the properties of phage L 80. Lysogenization of the non-lysogenic strain 57 with phage L80 produced an analogous change in phage pattern. The 
$\beta$-Toxin and kinase in staphylococci

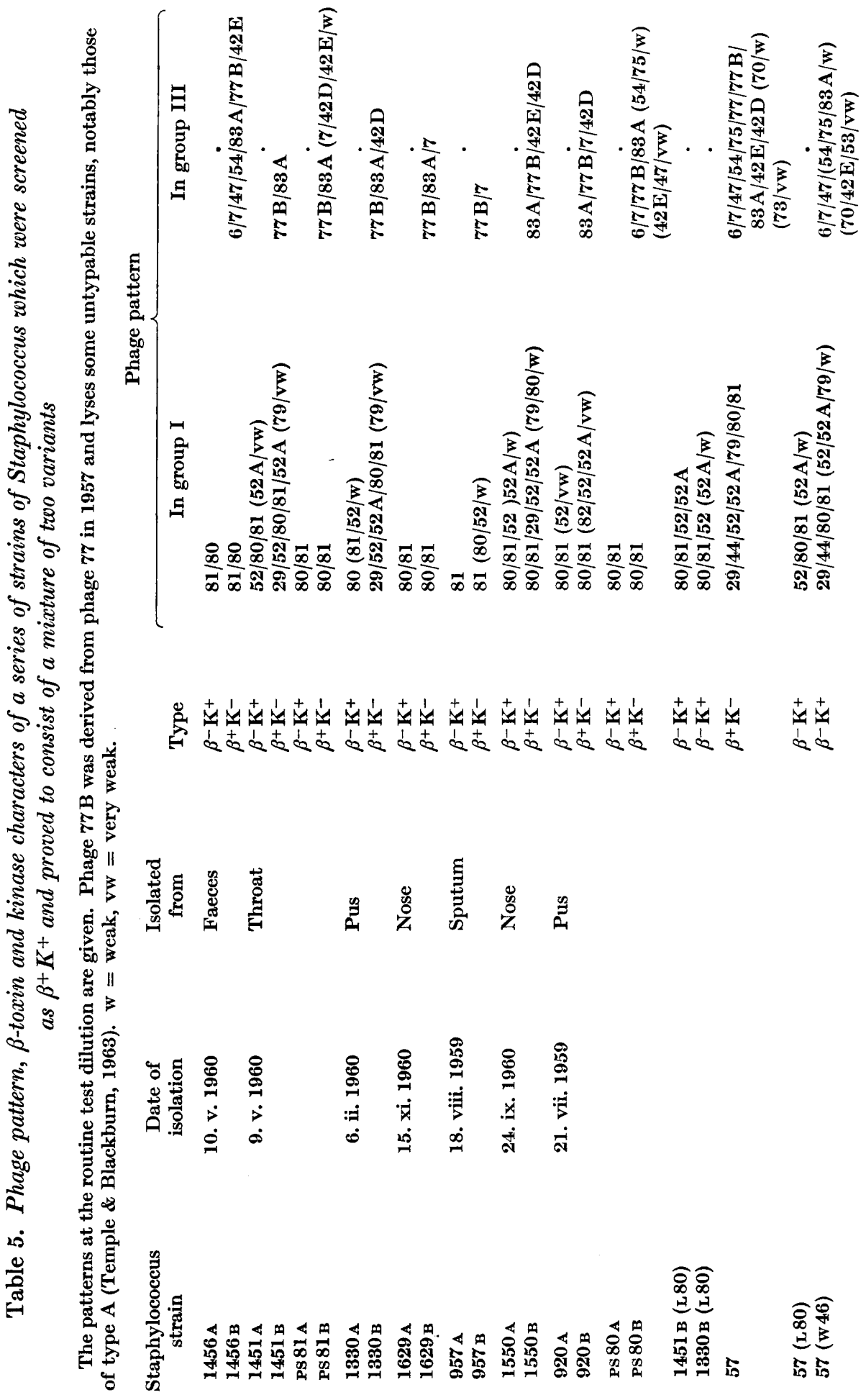


relation between conversion of phage pattern and conversion to $\beta^{-} \mathbf{K}^{+}$is however more or less fortuitous, as is shown by the conversion of strain 57 with phage W46 to $\beta^{-} \mathbf{K}^{+}$without change of pattern.

\section{Mechanism of conversion}

Activity of the converting loci in the prophage state. Phage conversion can be of two types. In the conversion of Corynebacterium diphtheriae to toxigenicity the toxin is produced only after phage production and lysis (Barksdale, Garmise \& Rivera, 1961; Zabriskie, 1964). The converting gene of the phage seems to be active

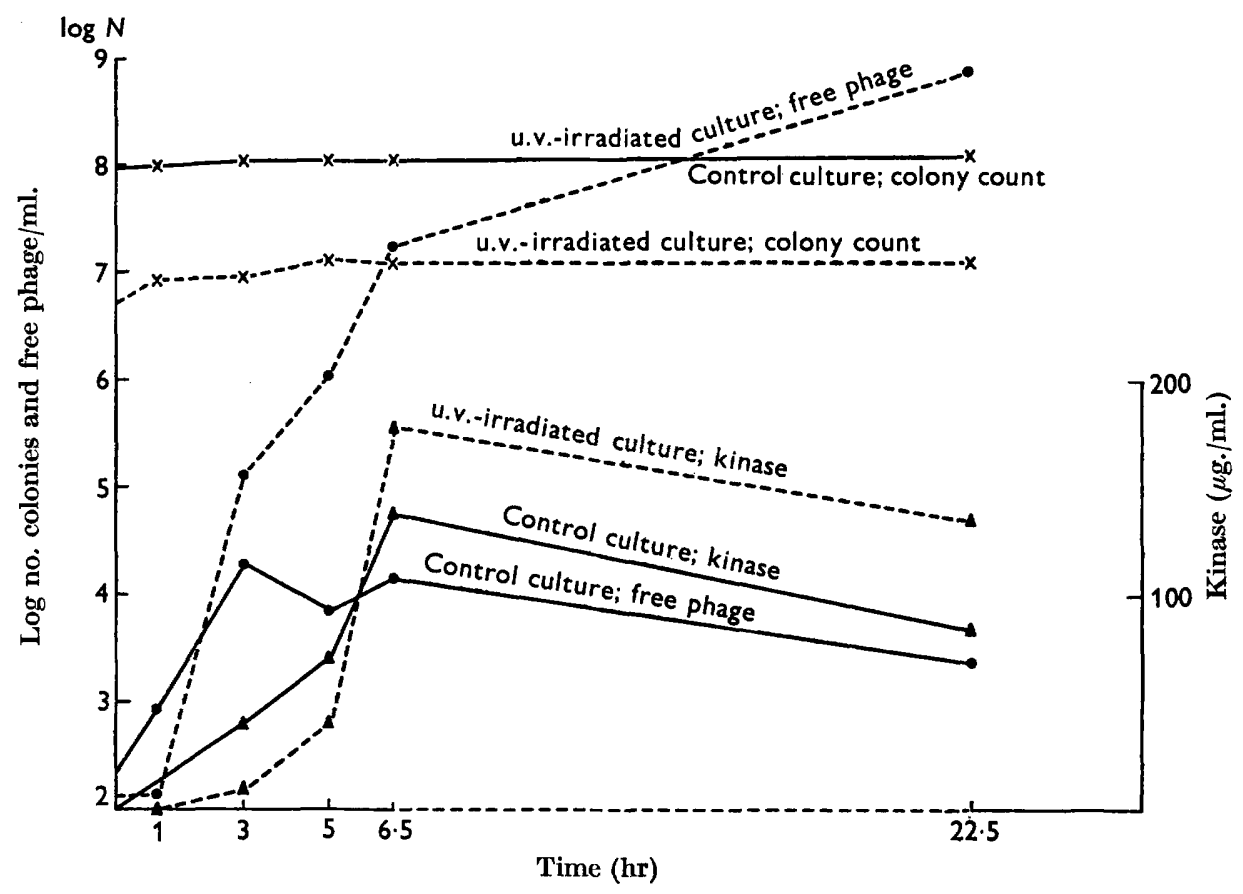

Fig. 1. Staphylococci of strain 269 (269) harvested from a $16 \mathrm{hr}$ culture at $30^{\circ}$ were suspended in $60 \mathrm{ml}$. 0.15 M-phosphate buffer (pH 6.8). Twelve $2 \mathrm{ml}$. samples were u.v.irradiated on a rotating disk during 10 sec. at $13 \mathrm{~cm}$. distance from a Philips TUV tube. The u.v-irradiated suspensions were mixed, and $6 \mathrm{ml}$. of a Todd-Hewitt broth of 5 times usual strength were added. A control suspension was prepared in the same way but without irradiation. Both cultures were incubated for $6.5 \mathrm{hr}$ at $37^{\circ}$ with gentle shaking and then allowed to stand at room temperature for a further $16 \mathrm{hr}$. Colony counts were done by the technique of Miles \& Misra. Free phage was counted on a streptomycin-resistant indicator strain of staphylococcus on Difco nutrient agar plates containing $10 \mu \mathrm{g}$-streptomycin $/ \mathrm{ml}$. Kinase was determined on diffusion plates against a crude standard as described. - - - - - free phage; $x-\times, \times \cdots \times$, colony count; $\Delta-\Delta, \Delta--\Delta$, kinase activity.

during the vegetative phase of phage production but not in the prophage state (see however Pappenheimer, Miller \& Yoneda, 1962). On the other hand in the lysogenic conversion of Salmonella which results in changes of antigen the converting gene is active in the prophage state as well as in the vegetative state. In our case the locus converting to loss of $\beta$-toxin was obviously active in the prophage state, since $\beta$-toxin is not produced by these growing organisms. 
To test whether the conversion to kinase production belonged to one or the other group the relation between phage production and kinase production was studied for a lysogenic Staphylococcus strain. Part of a suspension of strain 269 (269) $\beta^{-} \mathrm{K}^{+}$ was induced by u.v.-irradiation; the other part was kept as a control. The staphylococcal colony count, the number of free phage particles and the kinase production were determined in both suspensions during the subsequent period. The results are shown in Fig. 1. The colony count decreased sharply during u.v.-irradiation but remained stationary thereafter. In the induced culture the number of free phage particles-after a latent period of about $1 \mathrm{hr}$-increased to over $10^{7}$ per ml. In the control culture the number of free phage particles remained about $10^{4}$. Kinase production was about equal in both suspensions. The decrease of kinase activity during the second period was probably due to inactivation by the non-multiplying cocci. As there is no important increase in kinase production in the induced culture, notwithstanding the decrease of the colony count by $90 \%$, this experiment indicated that kinase was not produced by lysing cocci. Kinase production thus seems to be a property of the lysogenized coccus and the kinase locus on the phage seems to be active in the prophage state.

The number of loci on the phage. The phage locus responsible for conversion to loss of Staphylococcus $\beta$-toxin production obviously must be some kind of regulator gene causing suppression of $\beta$-toxin production. The kinase locus might be a structural locus or a gene with a de-repressing effect. The correlation between loss of $\beta$-toxin production and kinase production might be fortuitous, implying two independent loci on the converting phages, or it might be due to one regulator gene on the phage with a repressive effect on $\beta$-toxin production and de-repressive for kinase. Since all isolated phages were $\beta-K^{+}$an attempt was made to obtain phage mutants of a different type. U.v.-irradiation of phage 269 for 45 sec. resulted in a 25-fold decrease of the number of plaque-forming units. At this time the number of host-range mutants for Staphylococcus strain Ps3A was maximal. The u.v.irradiated suspension was plated on Staphylococcus strain 269. Individual plaques (256) were taken out of the agar layer with a pipette and transferred to $1 \mathrm{ml}$. of a 2-hr culture of sensitive strain 269. Lysogenization was virtually complete at $24 \mathrm{hr}$. The cocci were plated on heated rabbit plasma agar for kinase production and on blood agar for $\beta$-toxin production. One $\beta^{+} \mathbf{K}^{+}$strain was found which easily lost phage and reverted to $\beta+\mathbf{K}-$. This strain yielded a phage which converted to kinase production but did not affect the $\beta$-toxin production $\left(\beta^{0} \mathbf{K}^{+}\right)$; that is, it had lost the locus for $\beta$-toxin repression. Though only one mutant phage was obtained, this experiment seems to prove that phage 269 contains two independent loci.

\section{DISCUSSION}

Fifteen phages separable into at least four unrelated groups have been described here which are able to convert Staphylococcus strains producing $\beta$-toxin to the loss of $\beta$-toxin production. The converting phages all belong to the serological group $\mathbf{F}$, but at least three $\mathbf{F}$ phages are known which do not convert. The loss of ability to produce $\beta$-toxin is virtually complete, since cultures grown under optimal conditions for $\beta$-toxin production yielded filtrates in which no $\beta$-toxin was detected by titration with and without antitoxin (Table 2). The loss of ability to produce 
$\beta$-toxin is generally accompanied by the gain of staphylokinase (Table 1 ). Most $\mathbf{F}$ phages thus produce the conversion from $\beta^{+} \mathbf{K}^{-}$to $\beta^{-} \mathbf{K}^{+}$, but this conversion has never been observed with phages of other serological groups. Staphylococcal kinase and $\beta$-toxin seem to be separate entities (Table 3 ). The various combinations $\beta^{+} \mathbf{K}^{-}, \beta^{-} \mathbf{K}^{+}, \beta^{-} \mathbf{K}^{-}$and $\beta^{+} \mathbf{K}^{+}$can occur in strains in which no phage can be detected (Table 4, row 1 ) so that structural genes for $\beta$ and $K$ seem to occur on the bacterial genome. Prophages (not of group F) can also be present in these strains without affecting these characters (Table 4, row 2). These non-converting phages presumably do not carry the genes $\beta$ or $\mathrm{K}$ ( $\beta^{0} \mathrm{~K}^{0}$ phages). The converting phages of group $\mathbf{F}$ generally are of the type $\beta^{-} \mathbf{K}^{+}$, converting $\beta^{+} \mathbf{K}^{-}$strains to $\beta^{-} \mathbf{K}^{+}$(Table 4 , column $\mathrm{C}$ ) or $\beta-\mathrm{K}^{-}$strains to $\beta^{-} \mathrm{K}^{+}$strains (column $\mathbf{B}$ ). No wild-type phages with other combinations were found.

From phage $269 \beta^{-} \mathrm{K}^{+}$a mutant was obtained which had lost the property of converting to loss of $\beta$-toxin production but which had kept the $\mathrm{K}^{+}$character, indicating that two loci on the phage genome were involved. Both loci were active in the prophage state. The $\beta$-locus may be regarded as a regulator gene, since it suppresses $\beta$-toxin production as long as the prophage is present in a strain, though $\beta$-toxin production is resumed in strains cured from phage. The kinase locus might be a structural or a de-repressing locus. The presence of a structural kinase locus in strains not carrying phage makes the second possibility slightly more attractive.

The isolation of $\beta^{-} \mathbf{K}^{+}$and $\beta^{+} \mathbf{K}^{-}$variants from old stock cultures of Staphylococcus strains with phage pattern $80 / 81$, and the demonstration that this variation was due to loss of a converting phage (Table 5) and also affects the phage-typing pattern, seems to indicate that many of these strains of Staphylococcus carry a converting phage. The isolation of the converting F phage L 80 from strain PS 80 and the conversions obtained with this phage confirm this. There is an apparent discrepancy in the fact that the converting phages from strains $1330 \mathrm{~A}$ and $1451 \mathrm{~A}$ can be demonstrated on strain Ps 80 which already carries phage L 80 . The phenomenon was observed repeatedly. Apart from speculations about more virulent phages overcoming the immunity due to phage L 80 we have no explanation.

The data in Table 5 seem to indicate that at least some $\mathbf{A}$ strains with phage pattern 80/81 might have arisen from the $B$ pattern by lysogenization with such $F$ phages. The hypothesis that all $\beta^{-} \mathbf{K}^{+}$strains carry a converting phage is difficult to verify. We have tested many $\beta^{-} \mathbf{K}^{+}$strains for converting phage without finding any. This may have been due to lack of suitable indicator strains, to double lysogenicity with a minority yield of converting phage, or to the presence of defective prophages. Even the demonstration of a structural kinase locus on the genome of a certain converting phage would probably mean only that it had been derived from a bacterial genome at an earlier period, and certainly does not exclude the presence of a kinase locus on the bacterial genome in another strain. We consequently believe that many Staphylococcus strains carry $\beta$ and K loci unaffected by phage. 


\section{REFERENCES}

Adams, M. H. (1959). Bacteriophages. New York and London: Interscience Publishers Inc.

Barksdale, L., Garmise, L. \& Rivera, R. (1961). Toxinogeny in Corynebacterium diphtheriae. J. Bact. 81, 527.

Blair, J. E. \& Williams, R. E. O. (1961). Phage typing of staphylococci. Bull. Wld Hith Org. 24, 771.

Christie, R. \& Wilson, H. (1941). A test of staphylococcal fibrinolysin. Aust. J. exp. Biol. med. Sci. 19, 329.

Gerheim, E. B. (1948). Staphylococcal coagulation and fibrinolysis. Nature, Lond., 162, 732.

Gerheim, E. B., Ferguson, J. H. \& Travis, B. L. (1947). Activation of staphylocoagulase. Proc. Soc. exp. Biol. Med. 66, 525.

Gerheim, E. B., Ferguson, J. H. \& Travis, B. L. (1948). Staphylocoagulase and staphylokinase. Fed. Proc. 7, 41.

Gerheim, E. B., Ferguson, J. H., Travis, B. L., Johnston, C. L. \& Boyles, P. W. (1948). Staphylococcal fibrinolysis. Proc. Soc. exp. Biol. Med., 68, 246.

Glanville, K. L. (1963). A simple method of purifying staphylokinase. Biochem. J. 88, 11.

Lack, C. H. \& Wailling, D. G. (1954). A study of 435 strains of Staphylococcus pyogenes with reference to factors which may contribute to pathogenicity. J. Path. Bact. 68, 431.

Morse, S. I. (1962). Studies on the interactions between components of Staphylococcus aureus and staphylococcus bacteriophage. J. exp. Med. 116, 247.

Pappenheimer, A. M., Miller, P. A. \& Yoneda, M. (1962). Kinetics of diphtheria toxin formation. J. gen. Microbiol. 28, 531.

Rountree, P. M. (1947). Some observations on fibrinolysin and beta toxin of staphylococci. Aust. J. exp. Biol. med. Sci. 25, 359.

Rountree, P. M. (1959). Changes in the phage-typing patterns of staphylococci following lysogenization. J. gen. Microbiol. 20, 620.

Temple, N. E. I. \& Blackburn, E. A. (1963). A newly recognised strain of Staphylococcus aureus associated with epidemics in six hospitals. Lancet, $\mathrm{i}, 581$.

WAART, J. DE (1964). Lysogene conversie bij stafylococcen. Thesis, Utrecht, the Netherlands.

WAART, J. DE, Winkler, K. C. \& Grootsen, C. (1962). Lysogenic conversion in staphylococci. Nature, Lond. 195, 407.

Williams, R. E. O. \& Rippon, J. E. (1952). Bacteriophage typing of Staphylococcus aureus. J. Hyg., Camb. 50, 320.

Willis, A. T., JACOBS, S. I. \& Goodburn, G. M. (1963). Observations on multipleantibiotic-resistant epidemic strains of Staphylococcus aureus. Lancet, ii, 67.

WinkLER, K. C. \& Grootsen, C. (1961). The relation of phage pattern and lysogenicity in the phage typing of staphylococci of phage-group II. Antonie van Leeuwenhoek 27, 225.

ZABRISKIE, J. B. (1964). The Streptococcus, rheumatic fever and glomerulonephritis. Ed. by J. W. Uhr. Baltimore: The Williams and Wilkins Co. 